University of New Orleans

ScholarWorks@UNO

Advanced Materials Research Institute (AMRI) Advanced Materials Research Institute (AMRI)

3-5-2012

\title{
Towards One Key to One Lock: Catalyst Modified Indium Oxide Nanoparticle Thin Film Sensor Array for Selective Gas Detection
}

\author{
Kun Yao \\ Advanced Materials Research Institute, University of New Orleans, kyao1@uno.edu \\ Daniela Caruntu \\ University of New Orleans, dcaruntu@uno.edu \\ Sarah Wozny \\ University of New Orleans \\ Rong Huang \\ Nanostructures Research Laboratory, Japan Fine Ceramics Center \\ Yumi H. Ikuhara \\ Nanostructures Research Laboratory, Japan Fine Ceramics Center
}

See next page for additional authors

Follow this and additional works at: https://scholarworks.uno.edu/amri_facpubs

Part of the Materials Chemistry Commons, and the Physical Chemistry Commons

\section{Recommended Citation}

K. Yao, D. Caruntu, S. Wozny, R. Huang, Y.H. Ikuhara, B. Cao, C.J. O'Connor and W. Zhou, "Towards one key to one lock: catalyst modified indium oxide nanoparticle thin film sensor array for selective gas detection," J. Mater. Chem., 2012: 22, 7308.

This Article is brought to you for free and open access by the Advanced Materials Research Institute (AMRI) at ScholarWorks@UNO. It has been accepted for inclusion in Advanced Materials Research Institute (AMRI) by an authorized administrator of ScholarWorks@UNO. For more information, please contact scholarworks@uno.edu. 
Authors

Kun Yao, Daniela Caruntu, Sarah Wozny, Rong Huang, Yumi H. Ikuhara, Baobao Cao, Charles J. O'Connor, and Weilie Zhou 


\title{
Journal of

\section{Towards one key to one lock: catalyst modified indium oxide nanoparticle thin film sensor array for selective gas detection}

\author{
Kun Yao, ${ }^{a}$ Daniela Caruntu, ${ }^{a}$ Sarah Wozny, ${ }^{a}$ Rong Huang, ${ }^{b}$ Yumi H. Ikuhara, ${ }^{b}$ Baobao Cao, ${ }^{a}$ \\ Charles J. O'Connor ${ }^{a}$ and Weilie Zhou*a
}

\author{
Received 12th October 2011, Accepted 28th January 2012 \\ DOI: $10.1039 / \mathrm{c} 2 \mathrm{jm} 15179 \mathrm{k}$
}

\begin{abstract}
Homogeneous $\mathrm{In}_{2} \mathrm{O}_{3}$ nanoparticles (NPs) were self-assembled into thin film sensor arrays on a single chip, with further surface modification by noble metal catalysts. The NP film sensor arrays show clear current responses when exposed to different target gases, and both sensitivity and selectivity were greatly improved. Particularly, the sensors modified with $\mathrm{Au}, \mathrm{Pd}$, and Pt nanocatalysts demonstrated higher sensitivity to $\mathrm{H}_{2} \mathrm{~S}, \mathrm{H}_{2}$ and $\mathrm{CO}$, respectively, making the gas discrimination direct and simple, like "one key to one lock". The particle size dependence of the noble metal modifiers to the sensitivity was further investigated by tuning the sputtering parameters. Three different trends of sensitivities were observed, each attributed to different mechanisms. The modified nanoparticle film sensor was also fabricated on flexible substrates and the sensing performance was investigated at different bending angles.
\end{abstract}

\section{Introduction}

Chemical sensing is one of the most promising applications for nanomaterials, showing extremely high sensitivity resulting from the large surface-to-volume ratio. Numerous studies on pursuing novel nanomaterials or nanostructures have been reported to improve the sensitivity to multiple target gases. ${ }^{1-6}$ Selectivity, however, is another crucial parameter in sensing applications that has become an unavoidable obstacle which urgently needs to be overcome to realize gas sensors with "one key to one lock" performance. Since the dominating sensing mechanism in current nanomaterials, especially metal oxide based sensors, is related to the surface depletion region as well as the electric signal variation induced by the adsorbed chemical species, many reducing or oxidizing gases may cause similar current increase or decrease in the signal in n-type nanomaterials, ${ }^{7-10}$ making it hard for gas discrimination. In order to solve this issue, different sensor arrays are expected to be assembled together to work as an "electronic nose", where they should have as many different sensing capabilities as possible to discriminate different gases.

Several improvements on selective sensors were reported in recent years. Kolmakov's group assembled a chemical sensor array of $\mathrm{SnO}_{2}$ nanowires by temperature gradient and different nanowire densities (KAMINA technology), using linear discrimination analysis (LDA) to demonstrate the discrimination power quantitatively. ${ }^{11}$ They also investigated gas discrimination

${ }^{a}$ Advanced Materials Research Institute, University of New Orleans, New Orleans, LA 70148, USA. E-mail: wzhou@uno.edu; Fax: +1 (504) 2803185; Tel: +1 (504) 280-1068

${ }^{b}$ Nanostructures Research Laboratory, Japan Fine Ceramics Center, Nagoya 456-8587, Japan with an array of individual metal oxide nano- and mesowire sensors. ${ }^{12}$ Zhou's group integrated four different semiconducting nanowire or nanotube sensors with separate accurate temperature control, and used principal component analysis (PCA) to show the discrimination of different gases. ${ }^{13,14}$ Besides, surface modification has been proved to be an extremely effective way to improve the sensitivity in many sensors, ${ }^{15,16}$ as well as a potential method for enhancing selectivity by selecting suitable modifiers. ${ }^{17-20}$ However, it should be noticed that many data processing or analysis methods have to be employed in these reports for gas discrimination, sometimes with overlapping zones for different gases detection, making the discrimination indirect. In addition, little research has been performed for NP based sensors which have the advantages of easy assembly, large area, homogeneity, structure stability, and high surface/volume ratio. Therefore, novel materials and techniques are still being explored to enlarge the difference between the individual sensor units as well as the selectivity to make the discrimination method simple and direct.

In our previous works, we have demonstrated the superior sensitivities of metal oxide nanoparticles (NPs) to different target gases at room temperature, and found that surface modification is the most crucial factor to improve the sensitivity. ${ }^{8,16,20}$ In this work, we further study $\operatorname{In}_{2} \mathrm{O}_{3} \mathrm{NP}$ sensor arrays assembled on one chip, with the surface modification by different noble metals ( $\mathrm{Au}$, $\mathrm{Pd}$ and $\mathrm{Pt}$ ), to investigate selectivity at room temperature. We also tuned the metal modifier sizes and investigated their influence on sensing performance. The mechanisms associated with each modifier were explored. Such a modified nanoparticle film sensor array was further fabricated on a flexible substrate and the bending test demonstrated robust performance. 


\section{Experimental}

The $\mathrm{In}_{2} \mathrm{O}_{3}$ NPs used in this work were prepared via a chemical solution method, involving thermal decomposition of metalorganic precursors in fatty alcohol solutions at $320{ }^{\circ} \mathrm{C}$. The diameter of the particles obtained is 6-10 nm. ${ }^{8}$ After the deposition and annealing procedures addressed in our previous work ${ }^{20}$ the nanoparticles formed a short-range ordered thin film on a $\mathrm{Si} / \mathrm{SiO}_{2}$ substrate, with homogeneous and controlled thickness. An array of $40 \mathrm{~nm}$ thick Au contact pads was deposited using a resist free shadow mask evaporation method (Lesker PVD 75), forming multiple sensors on one chip. Different metals ( $\mathrm{Au}, \mathrm{Pd}$ and $\mathrm{Pt}$ ) were then sputtered (Cressington 308R) one by one onto individual $\operatorname{In}_{2} \mathrm{O}_{3} \mathrm{NP}$ film sensors for surface modification, where they kept separated as nanoparticles instead of a continuous film. ${ }^{16}$ For comparison purposes, one sensor was left as a bare NP film without any modification. The schematic of the device fabrication is illustrated in Fig. 1(a)-(d). Fig. 1(e) shows an SEM image of the NP film on the $\mathrm{SiO}_{2}$ substrate from a tilted view, where both the smooth surface and the cross-section can be observed. Actually, this NP film, as well as devices, can also be obtained on many types of substrates including flexible substrates, as shown in Fig. 1(f), which implies that such NP films have broad applications. For sensing investigation, the sensors were mounted in a custom-designed sealed chamber with an electrical feedthrough and gas inlet/outlet. The data were collected by Keithley 2400 and 4200 source meters. To compare these sensors accurately and objectively, all the other parameters were kept almost the same during fabrication $\left(\mathrm{In}_{2} \mathrm{O}_{3}\right.$ film thickness: $400 \mathrm{~nm}$, electrode gap: $100 \mu \mathrm{m}$, electrode width: $500 \mu \mathrm{m}$, nominal thickness of metal deposited: $0.4 \mathrm{~nm}$ ). $I-V$ curves from all of these sensors are

(a)

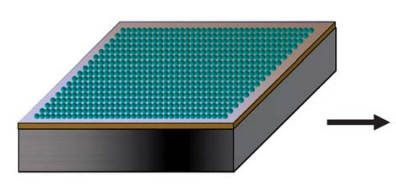

(b)

(d)
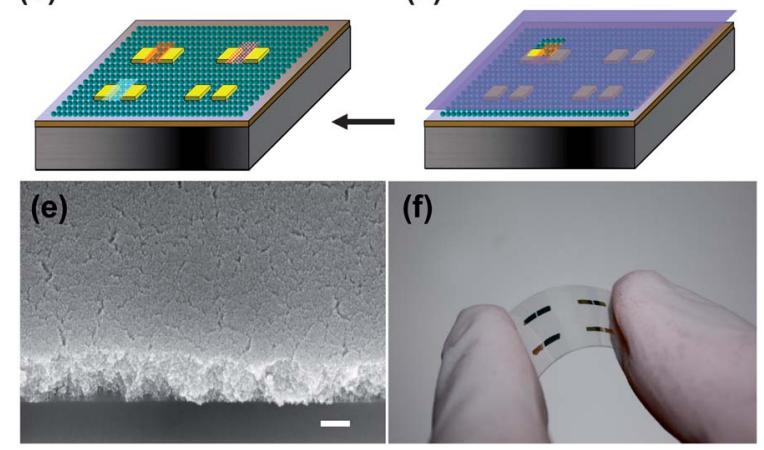

Fig. 1 Schematic of device fabrication: (a) $\operatorname{In}_{2} \mathrm{O}_{3}$ nanoparticle film. (b) Au electrode array deposition using a resist free shadow mask. (c) Surface modification one by one via sputtering using a second mask. (d) Multiple devices on one chip. (e) SEM image of the nanoparticle film on the $\mathrm{SiO}_{2}$ substrate from a tilted view. The scale bar is $200 \mathrm{~nm}$. (f) Photograph of sensor arrays on a flexible and transparent substrate. linear, implying good contact between NPs and electrodes as we reported before. ${ }^{20}$

\section{Results and discussion}

Fig. 2(a)-(d) show the current responses of the four sensors to air-diluted $\mathrm{H}_{2} \mathrm{~S}$ with different concentrations of $0 \mathrm{ppb}, 20 \mathrm{ppb}$, $200 \mathrm{ppb}, 2 \mathrm{ppm}, 20 \mathrm{ppm}$ and $200 \mathrm{ppm}$ at a $0.2 \mathrm{~V}$ bias. For n-type $\mathrm{In}_{2} \mathrm{O}_{3}$ NP films, reducing gas $\mathrm{H}_{2} \mathrm{~S}$ reacts with the adsorbed oxygen, decreases the depletion region around $\mathrm{In}_{2} \mathrm{O}_{3} \mathrm{NPs}$, and increases the current. Air flow is easy to make the recovery in several minutes. Due to the particular structure of multiple NP layers, there exists an equilibrium of oxygen adsorption and desorption, leading to a slow current increase even in $0 \mathrm{ppb} \mathrm{H}_{2} \mathrm{~S}$ after stopping air flow. ${ }^{20}$ Fig. 2(e) presents the sensitivities $(S)$ of the sensors to $\mathrm{H}_{2} \mathrm{~S}$ with different concentrations considering a response time of 30 minutes, where $S$ is defined as $S=\left(G_{\text {gas }}-G_{\text {air }}\right) / G_{\text {air }} \times 100 \%\left(G_{\text {gas }}\right.$ and $G_{\text {air }}$ are the conductance in diluted $\mathrm{H}_{2} \mathrm{~S}$ and air, respectively). Obviously, all the sensors with surface modification have a substantial improvement of sensitivity and a lower detection limit by several orders. However, such improvement differs in the three modified sensors, where Au modified sensor exhibits the highest sensitivity (noticing the logarithmic coordinate axis).

Two other important reducing target gases, $\mathrm{H}_{2}$ and $\mathrm{CO}$, were then also investigated. Fig. 3(a) and (b) show the sensitivities of the sensors to $\mathrm{H}_{2}$ and $\mathrm{CO}$ of different concentrations. Again, the modified sensors show better sensing performance than the bare NP film sensor. The Pd modified sensor exhibits the highest sensitivity to $\mathrm{H}_{2}$ and the Pt modified sensor presents the highest sensitivity to $\mathrm{CO}$. From the experimental results, there are several things worthy of being noted: first, the extremely high sensitivity and low detection limit are attributed to both NP film structure and the noble metals; therefore the detection abilities for all three gases $\left(\mathrm{H}_{2} \mathrm{~S}: 20 \mathrm{ppb}, \mathrm{H}_{2}: 8 \mathrm{ppm}, \mathrm{CO}: 20 \mathrm{ppm}\right)$ are close to the best reported room-temperature sensors based on metal oxide nanomaterials, ${ }^{20-22}$ showing an extremely low detection limit and high sensitivity. Second, all three noble metals improve the sensing performance, each with different level of improvement. Therefore, we are able to compare the impact of different metals and evaluate the large amount of reported results where mostly only one noble metal was used to modify the sensor. Third, the gas discrimination becomes direct and clear by checking which sensor exhibits the highest sensitivity, because $\mathrm{Au} / \mathrm{Pd} / \mathrm{Pt}$ modified sensors show especially high sensitivity to the respective gases of $\mathrm{H}_{2} \mathrm{~S} / \mathrm{H}_{2} / \mathrm{CO}$. For example, if the Pt modified sensor shows the highest sensitivity to a target gas, it simply indicates that the detecting gas is $\mathrm{CO}$.

Furthermore, we tuned the sizes of these noble metal nanocrystals by the power rate and duration of sputtering to optimize the sensitivity, and observed sensing trends. Since these metals were generally discussed as the catalysts to provide an alternative reaction pathway with lower activation energy, ${ }^{23,24}$ smaller particles were expected to show better performance due to the larger surface area. The nominal thickness of the deposited metal was used to estimate the size of the metal nanocrystals, which was further verified by transmission electron microscopy (TEM) observation. In detail, when the nominal thickness of Pt is controlled to be $0.1,0.2$ and $0.4 \mathrm{~nm}$, the actual size of the $\mathrm{Pt}$ 

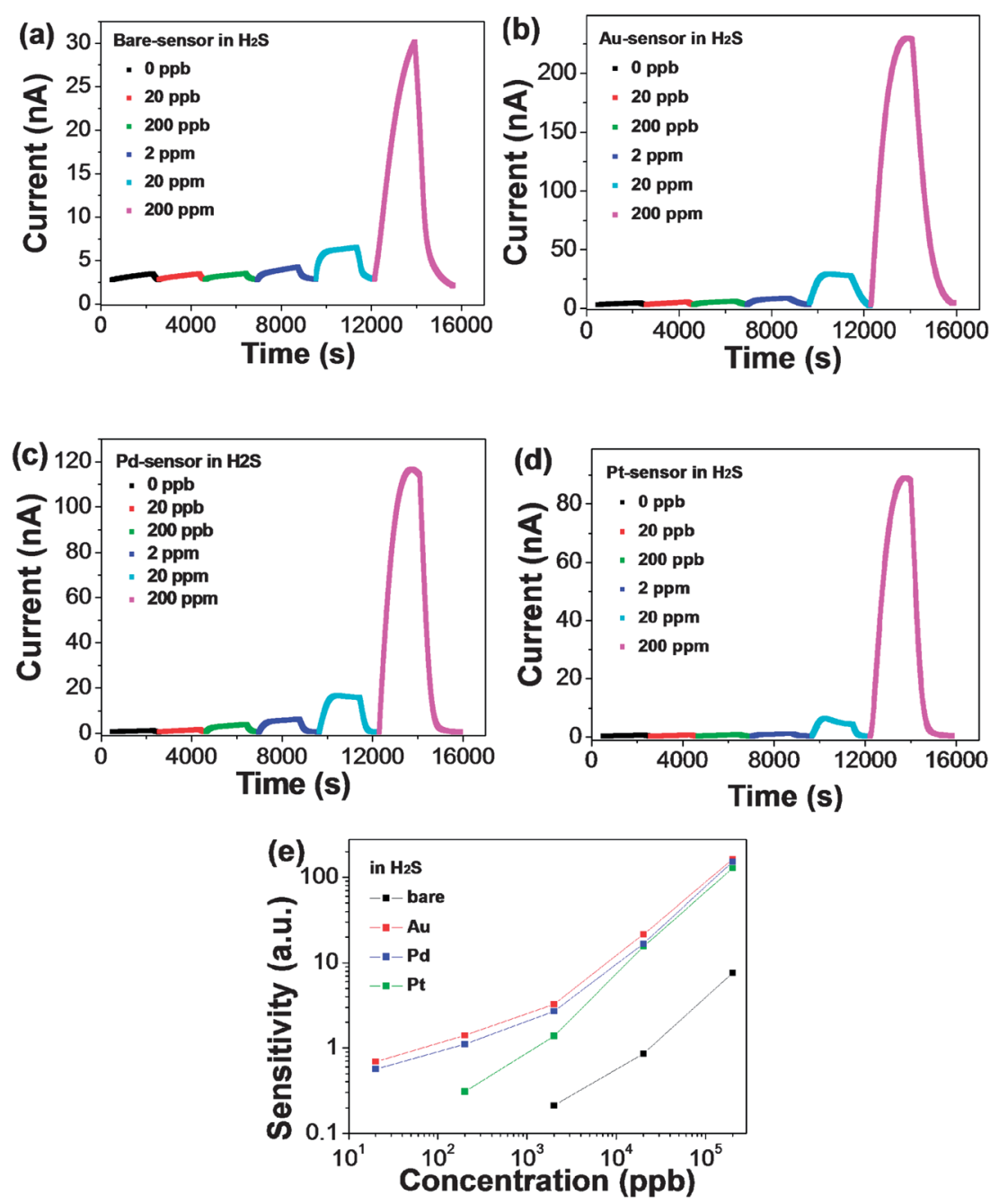

Fig. 2 (a-d) Current responses of the four sensors to air-diluted $\mathrm{H}_{2} \mathrm{~S}$ with different concentrations of $0 \mathrm{ppb}, 20 \mathrm{ppb}, 200 \mathrm{ppb}, 2 \mathrm{ppm}, 20 \mathrm{ppm}$ and 200 ppm at $0.2 \mathrm{~V}$ bias. (e) Sensitivities of the four sensors to $\mathrm{H}_{2} \mathrm{~S}$ with different concentrations.

nanocrystals observed is about sub- $1 \mathrm{~nm}, 1 \mathrm{~nm}$ and $2 \mathrm{~nm}$ by highangle annular dark-field scanning transmission electron microscopy (HAADF-STEM) observation, respectively. To prepare the TEM samples, $\mathrm{In}_{2} \mathrm{O}_{3}$ NP solution was first diluted and dropped onto several TEM grids. Then these TEM grids were put into the deposition system one by one along with the thin film sensor array for individually controlled surface modifications. The density of the Pt nanocrystals did not change obviously, implying a Volmer-Weber growth mode. ${ }^{25}$ Such results are shown in Fig. 4, where the larger nanoparticles are $\mathrm{In}_{2} \mathrm{O}_{3}$ NPs and the relatively small nanoparticles are $\mathrm{Pt}$ nanocrystals. In the same way, we also succeeded in tuning the size of $\mathrm{Au}$ and $\mathrm{Pd}$. To investigate the size influence of each metal on sensing performance, four sensors (including three modified by different metal nanocrystal sizes and one bare NP sensor) were fabricated on one chip to detect the corresponding target gases. Fig. 5(a)-(c) show the sensitivities of $\mathrm{Au}, \mathrm{Pd}$, and $\mathrm{Pt}$ modified sensors to their corresponding gases $\mathrm{H}_{2} \mathrm{~S}, \mathrm{H}_{2}$ and $\mathrm{CO}$, after nanocrystal size has been tuned, respectively. As the metal nanocrystal size is increased, the sensitivity of $\mathrm{Au}$ modified sensors to $\mathrm{H}_{2} \mathrm{~S}$ shows a weak increase while the sensitivity of $\mathrm{Pd}$ modified sensors to $\mathrm{H}_{2}$ presents a strong increase. However, it is opposite for Pt modified sensors, where the sensitivity to CO increased as the nanocrystal size is decreased. The results clearly illustrate three different direct trends and demonstrate a method of designing a sensor with improved sensitivity and selectivity, simultaneously. The sensing mechanisms associated with these three different metal nanocrystal modifications are also discussed in the following.

Based on previous reports, ${ }^{3,7,20}$ for n-type $\operatorname{In}_{2} \mathrm{O}_{3}$ nanoparticles, there is usually a surface depletion region derived from the chemisorption of oxygen, which immobilizes the electron carriers and determines the current transport. At room temperature, reducing gases react with the chemisorbed oxygen, speed up the reduction of the depletion region, release electron carriers back to the nanoparticles, and increase the current, as shown by the following chemical equations: $:^{3,14}$

$$
\begin{gathered}
\mathrm{H}_{2}+\mathrm{O}^{-} \rightarrow \mathrm{H}_{2} \mathrm{O}+\mathrm{e} \\
\mathrm{CO}+\mathrm{O}^{-} \rightarrow \mathrm{CO}_{2}+\mathrm{e} \\
\mathrm{H}_{2} \mathrm{~S}+3 \mathrm{O}^{-} \rightarrow \mathrm{H}_{2} \mathrm{O}+\mathrm{SO}_{2}+3 \mathrm{e}
\end{gathered}
$$



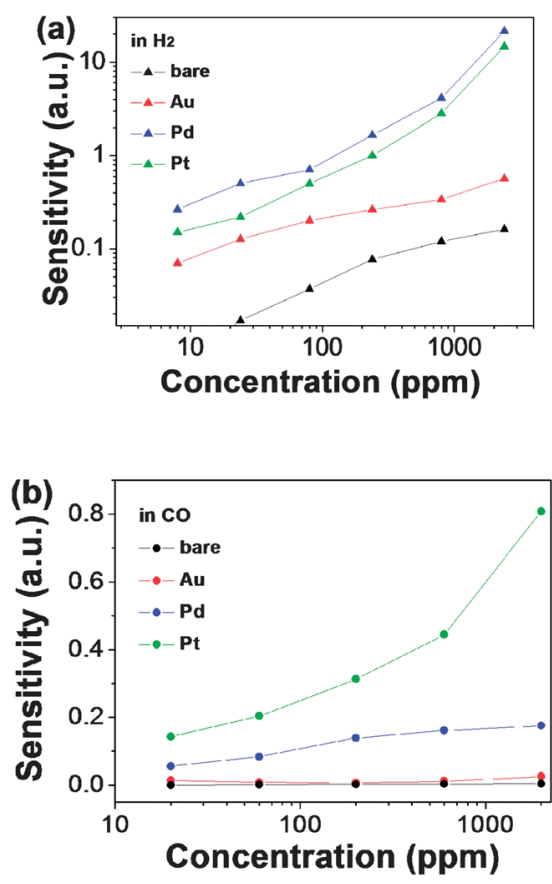

Fig. 3 Sensitivities of the four sensors to (a) $\mathrm{H}_{2}$ and (b) $\mathrm{CO}$ with different concentrations.
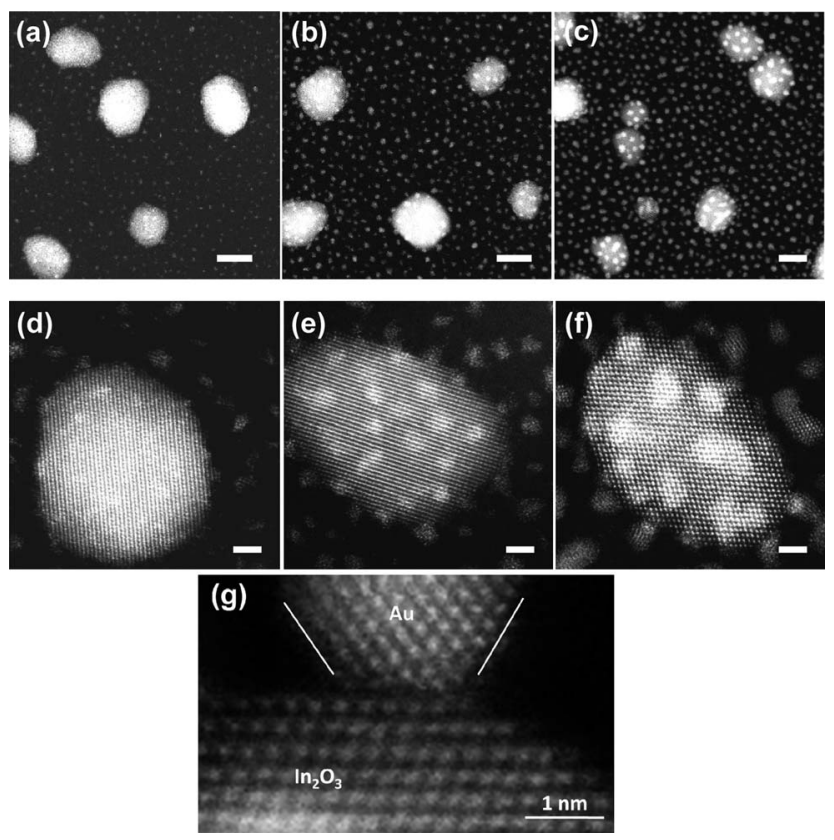

Fig. 4 (a-c) HAADF-STEM images of Pt nanocrystals with the nominal thickness of $0.1,0.2$, and $0.4 \mathrm{~nm}$ in low magnification. The scale bar is $10 \mathrm{~nm}$. (d-f) HAADF-STEM images of Pt nanocrystals with the nominal thickness of $0.1,0.2$, and $0.4 \mathrm{~nm}$ in high magnification. The scale bar in (a)-(f) is $2 \mathrm{~nm}$. (g) A HAADF-STEM image of a Au nanocrystal on the surface of an $\mathrm{In}_{2} \mathrm{O}_{3}$ nanoparticle, where $\{111\}$ facets are highlighted by white lines.

From our experimental results, we see that the noble metals sputtered for the purpose of surface modification definitely play a significant role in improving both sensitivity and selectivity. However, different mechanisms instead of the generally
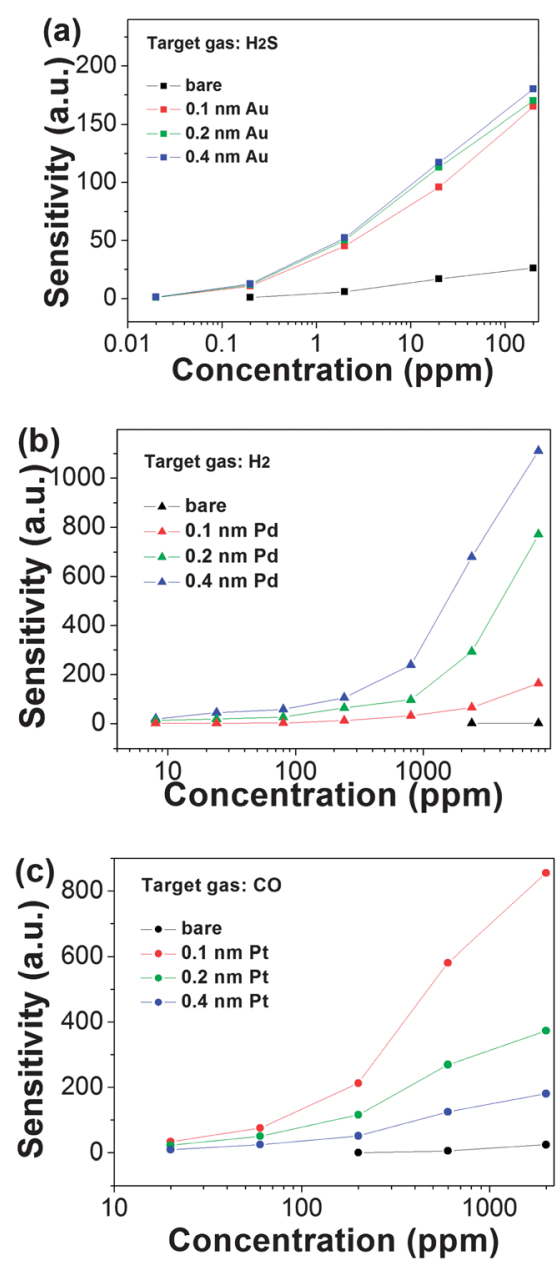

Fig. 5 (a-c) Sensitivities of $\mathrm{Au}, \mathrm{Pd}$, and Pt modified sensors to their corresponding gases $\mathrm{H}_{2} \mathrm{~S}, \mathrm{H}_{2}$, and $\mathrm{CO}$, with metal size tuning respectively.

discussed catalysis mechanism correspond with the variations of sensing performance associated with varying metal nanocrystal sizes. Due to the well-known mechanism of the highly efficient dissolution of $\mathrm{H}_{2}$ into $\mathrm{Pd}$, the interaction between $\mathrm{H}_{2}$ and $\mathrm{Pd}$ would follow a particular mechanism. ${ }^{26,27}$ Therefore, Pd catalysts of larger size adsorb more $\mathrm{H}_{2}$ molecules and show higher sensitivity. For the other gases and metal nanocrystals, the adsorption energy was widely used to predict the chemical activity of the surface, ${ }^{28,29}$ which was further employed to explain the mechanism. From the HAADF-STEM image, $\{111\}$ facets of Au metal nanocrystals can be clearly observed, as shown in Fig. 4(g). The size of all the noble metal nanocrystals was about $2 \mathrm{~nm}$ or less by controlling the parameters of sputtering, where the majority crystal face exposed in the atmosphere was ascertained to be (111) according to many experimental and theoretical studies on the metal nanocrystals with such a size range. ${ }^{30-32}$ Many researchers have considered the adsorption energy of $\mathrm{H}_{2} \mathrm{~S}$ and $\mathrm{CO}$ molecules on (111) metal surfaces using density functional theory (DFT) calculations, ${ }^{28,29}$ and some results are summarized in Table 1. For CO target gas, the adsorption energy on $\mathrm{Pt}$ is the lowest, leading to the highest binding affinity and sticking coefficient with Pt among these three kinds of metals, which matches 
Table 1 Adsorption energy of $\mathrm{CO}$ and $\mathrm{H}_{2} \mathrm{~S}$ on (111) surfaces of $\mathrm{Au}, \mathrm{Pt}$, and $\mathrm{Pd}$ from ref. 25 and 26 (units in $\mathrm{eV}$ )

\begin{tabular}{lll}
\hline & \multicolumn{2}{l}{ Adsorbed gas } \\
\cline { 2 - 3 } Surface & $\mathrm{CO}$ & $\mathrm{H}_{2} \mathrm{~S}$ \\
\hline $\operatorname{Au}(111)$ & -0.04 & -0.27 to -0.5 \\
$\operatorname{Pt}(111)$ & -1.45 & -0.51 to -0.91 \\
$\operatorname{Pd}(11)$ & -1.30 & -0.61 to -0.75 \\
\hline
\end{tabular}

our sensing results very well. Also, smaller sized Pt nanocrystals have higher surface to volume ratio which can increase the sensitivity to $\mathrm{CO}$. However, for $\mathrm{H}_{2} \mathrm{~S}$ target gas, the adsorption energy on $\mathrm{Au}$ is not the lowest, which indicates that adsorption energy is not the most crucial criterion. The strong bond between $\mathrm{S}$ and $\mathrm{Au}$ (forming "alligator clips") has been widely reported in the past few years, demonstrating that strong gold-sulfur bonding in alkylthiol self-assembled monolayers on gold particle surface results in the form of $\mathrm{Au}-\mathrm{SR}$ ( $\mathrm{R}$ : alkyl chain), with the loss of the thiol hydrogen in the bond formation process. ${ }^{33,34}$ Direct adsorption of $\mathrm{H}_{2} \mathrm{~S}$ onto the gold (111) surface has been studied with the temperature-programmed desorption and X-ray photoelectron spectroscopy, showing that $\mathrm{H}_{2} \mathrm{~S}$ molecules can easily undergo adsorption and desorption molecularly. ${ }^{35}$ Therefore, the unique bond between gold and sulfur atoms in a sulfur compound is probably the reason for the good selectivity. Furthermore, since the noble metal nanocrystals are discontinuous, the NP film is still the real conducting channel. Thus, the interaction between the gas molecule and noble metal is one factor and the other one should be the electron transfer from the noble metal to the $\operatorname{In}_{2} \mathrm{O}_{3}$ nanoparticle to contribute to the current signal. The adsorption of $\mathrm{H}_{2} \mathrm{~S}$ molecules onto $\mathrm{Au}$ nanoparticles has been reported to significantly change the hopping behavior of electrons through the Au particles, ${ }^{36}$ which may be the reason for the size effect of Au. However, based on our current knowledge, although a lot of studies have discussed the noble metal modified metal oxide sensors, the mechanism has not been fully understood yet, which needs further theoretical study.

Additionally, insulative fluorocarbon film (DuPont FEP), as a transparent flexible substrate, was employed for such nanoparticle film sensor fabrication using the same resist free shadow mask evaporation method (shown in Fig. 1(f)). The sensing performance was also further investigated at different bending angles, by using two SEM cross-sectional stages to fix the DuPont FEP film substrate and controlling its bending angle through adjusting the distance of the two SEM cross-sectional stages. The fabrication of sensor array on a flexible substrate allows the board to conform to a desired shape or to flex during its use, providing the possibility to fabricate multiple functional devices. Fig. 6(a) shows the schematic of film bending, where the positive or negative bending angle $\theta$ is defined respectively. Fig. 6(b) and (c) show the static linear $I-V$ curves and dynamic repeatable current variation of an Au-modified NP sensor at different bending angles, illustrating the robust performance of the film as well as the contact between the NPs. The current increase at positive bending angles is due to the compression of the NP film and more compact contact between NPs. The current decrease at negative bending angles is due to the stretching of the NP film and looser contact between NPs. According to our previous work, the contacts between NPs determine the conducing channels in the NP film, influence the equilibrium between gas adsorption and desorption, and have an impact on the sensing properties. ${ }^{16,20}$ Therefore, the positive bending is expected to enhance the sensitivity and the negative bending is (a)
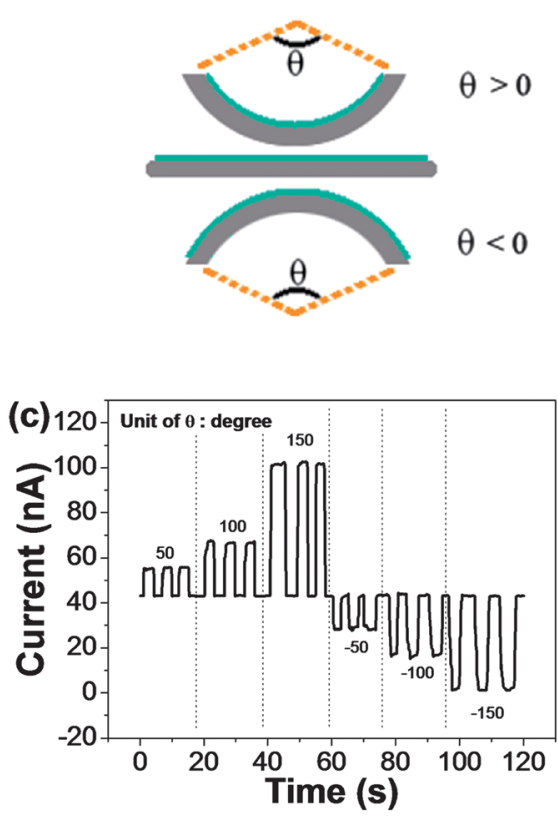
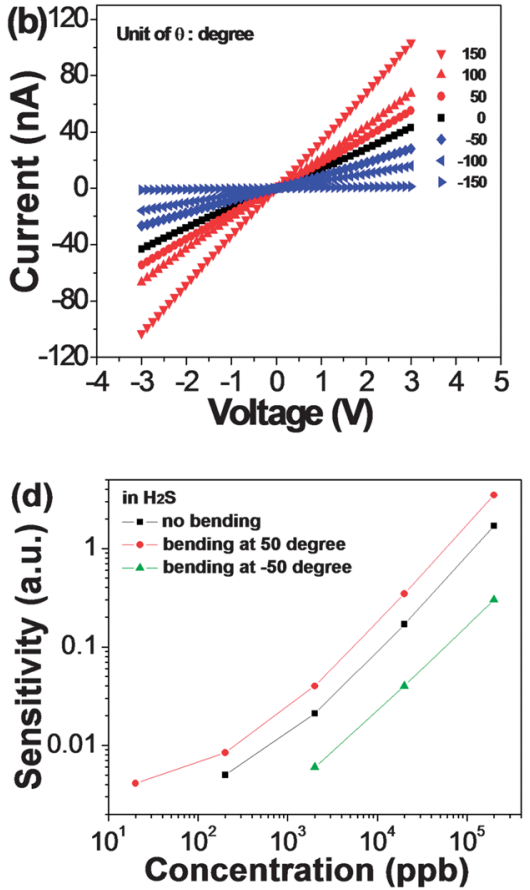

Fig. 6 (a) Schematic of the substrate bending, with NP film on the top surface. (b) $I-V$ curves of a NP film sensor at different bending angles. (c) Dynamic current response at different bending angles, at a voltage bias of $3 \mathrm{~V}$. (d) Sensitivities of the NP film sensor to $\mathrm{H}_{2} \mathrm{~S}$ at different bending angles. 
expected to lower the sensitivity, which is further verified in the $\mathrm{H}_{2} \mathrm{~S}$ detection test as shown in Fig. 6(d). To the best of our knowledge, this is the first study of nanoparticle-based chemical sensing performance on dependence of bending angles of flexible substrates, which is believed to be helpful for the future design and application of sensors on flexible substrates. In addition, compared to Fig. 2(e), the sensing performance shown in Fig. 6(d) is relatively lower, which is due to different levels of surface modification. In Fig. 6, the study was focused on the bending effect and the fabrication did not follow the previous multi-step deposition for precisely controlled surface modification. Instead, $\mathrm{Au}$ electrodes were deposited via sputtering, leading to an unintentional $\mathrm{Au}$ surface modification which was weaker than a well controlled surface modification. ${ }^{20}$

\section{Conclusions}

In summary, we assembled $\operatorname{In}_{2} \mathrm{O}_{3}$ nanoparticle films on different substrates and engineered the surface with different noble metals to achieve multiple sensors on one chip. All the sensors have better performance after surface modification, and different sensors modified with $\mathrm{Au}, \mathrm{Pt}$, and $\mathrm{Pd}$ demonstrated particular high responses to $\mathrm{H}_{2} \mathrm{~S}, \mathrm{CO}$, and $\mathrm{H}_{2}$, respectively. By tuning the size of the metal nanocrystals, three different trends of sensitivity were observed. Although it is hard to find the suitable modifier for every gas, it has been proved that such a "one key to one lock" design is promising in a certain range of gases, with both high sensitivity and selectivity simultaneously. For future applications, the challenge remains the exploration of more modifiers and their corresponding gases to enlarge the library.

\section{Acknowledgements}

Kun Yao thanks Dr Ting Zhang at HKUST for the discussion of the sensing mechanism. This work was supported by DARPA Grant No. HR0011-07-1-0032, research grants from Louisiana Board of Regents Contract Nos. LEQSF(2007-12)-ENHPKSFI-PRS-04, LEQSF(2008-11)-RD-B-10, and LEQSF(201113)-RD-B-08, and American Chemical Society Petroleum Research Fund under PRF No. 48796-DN110.

\section{References}

1 J. Kong, N. R. Franklin, C. Zhou, M. G. Chapline, S. Peng, K. Cho and H. Dai, Science, 2000, 287, 622.

2 Y. Cui, Q. Wei, H. Park and C. M. Lieber, Science, 2001, 293, 1289

3 A. Kolmakov and M. Moskovits, Annu. Rev. Mater. Res., 2004, 34, 151.

4 D. Zhang, Z. Liu, C. Li, T. Tang, X. Liu, S. Han, B. Lei and C. Zhou, Nano Lett., 2004, 4, 1919.
5 K. Yao, W. W. Gong, Y. F. Hu, X. L. Liang, Q. Chen and L.-M. Peng, J. Phys. Chem. C, 2008, 112, 8721.

6 K. Yao, Z. Y. Zhang, X. L. Liang, Q. Chen, L.-M. Peng and Y. Yu, J. Phys. Chem. B, 2006, 110, 21408.

7 M. Tiemann, Chem.-Eur. J., 2007, 13, 8376.

8 D. Caruntu, K. Yao, Z. Zhang, T. Austin, W. Zhou and C. J. O'Connor, J. Phys. Chem. C, 2010, 114, 4875.

9 J. Chen, K. Wang, R. Huang, T. Saito, Y. H. Ikuhara, T. Hirayama and W. Zhou, IEEE Trans. Nanotechnol., 2010, 9, 634.

10 A. Ponzoni, E. Comini, G. Sberveglieri, J. Zhou, S. Z. Deng, N. S. Xu, Y. Ding and Z. L. Wang, Appl. Phys. Lett., 2006, 88, 203101.

11 V. V. Sysoev, J. Goschnick, T. Schneider, E. Strelcov and A. Kolmakov, Nano Lett., 2007, 7, 3182.

12 V. V. Sysoev, B. K. Button, K. Wepsiec, S. Dmitriev and A. Kolmakov, Nano Lett., 2006, 6, 1584.

13 P. C. Chen, G. Shen and C. Zhou, IEEE Trans. Nanotechnol., 2008, 7, 669.

14 G. Shen, P. C. Chen, K. Ryu and C. Zhou, J. Mater. Chem., 2009, 19, 828.

15 A. Kolmakov, D. O. Klenov, Y. Lilach, S. Stemmer and M. Moskovits, Nano Lett., 2005, 5, 667.

16 K. Yao, D. Caruntu, B. Cao, C. J. O'Connor and W. Zhou, IEEE Trans. Nanotechnol., 2010, 9, 630.

17 M. C. McApline, H. Ahmad, D. Wang and J. R. Heath, Nat. Mater., $2007,6,1$.

18 Y. Lu, C. Partridge, M. Meyyappan and J. Li, J. Electroanal. Chem., 2006, 593, 105.

19 J. Chen, K. Wang and W. Zhou, IEEE Trans. Nanotechnol., 2011, 10, 968.

20 K. Yao, D. Caruntu, Z. Zeng, J. Chen, C. J. O'Connor and W. Zhou, J. Phys. Chem. C, 2009, 113, 14812.

21 N. Singh, C. Y. Yan and P. S. Lee, Sens. Actuators, B, 2010, 150, 19.

22 H. T. Wang, B. S. Kang, F. Ren, L. C. Tien, P. W. Sadik, D. P. Norton, S. J. Pearton and J. Lin, Appl. Phys. Lett., 2005, 86, 243503.

23 W. Xiong, F. Du, Y. Liu, Jr, A. Perez, M. Supp, T. S. Ramakrishnan, L. Dai and L. Jiang, J. Am. Chem. Soc., 2010, 132, 15839.

24 J. Xu, T. White, P. Li, C. He, J. Yu, W. Yuan and Y.-F. Han, J. Am. Chem. Soc., 2010, 132, 10398.

25 K. Oura, V. G. Lifshits, A. A. Saranin, A. V. Zotov and M. Katayama, Surface Science: an Introduction, Springer, Berlin, 2003.

26 F. Favier, E. C. Walter, M. P. Zach, T. Benter and R. M. Penner, Science, 2001, 293, 2227.

27 P. Offermans, H. D. Tong, C. J. M. van Rijn, P. Merken, S. H. Brongersma and M. Crego-Calama, Appl. Phys. Lett., 2009, 94, 223110.

28 B. Hammer, Y. Morikawa and J. K. Nørskov, Phys. Rev. Lett., 1996, 76, 2141.

29 D. R. Alfonso, Surf. Sci., 2008, 602, 2758.

30 Z. L. Wang, J. Phys. Chem. B, 2000, 104, 1153.

31 K. P. McKenna, Phys. Chem. Chem. Phys., 2009, 11, 4145.

32 L. Y. Chang, A. S. Barnard, L. C. Gontard and R. E. DuninBorkowski, Nano Lett., 2010, 10, 3073.

33 C. Vericat, M. E. Vela and R. C. Salvarezza, Phys. Chem. Chem. Phys., 2005, 7, 3258.

34 P. D. Jadzinsky, G. Calero, C. J. Ackerson, D. A. Bushnell and R. D. Kornberg, Science, 2007, 318, 430.

35 A. J. Leavitt and T. P. Beebe, Jr, Surf. Sci., 1994, 314, 23.

36 J. Geng, M. D. R. Thomas, D. S. Shepharda and B. F. G. Johnson, Chem. Commun., 2005, 1895. 